\title{
HLA antigens and atopy in children with coeliac disease
}

\author{
M VERKASALO, A TIILIKAINEN, P KUITUNEN, \\ E SAVILAHTI, AND A BACKMAN
} From the Children's Hospital, University of Helsinki, and Finnish Red Cross Blood Transfusion Service,
Helsinki, Finland

SUMmARY HLA antigens and various aspects of atopy were studied in 42 Finnish children and adolescents with coeliac disease, and the results were compared with findings of recent population studies. The HLA associations were as expected: relative risks for coeliac disease in individuals with HLA-B8, DR3, and DR7 were $8 \cdot 0,18 \cdot 6$, and $15 \cdot 0$, respectively. Children with coeliac disease were significantly more often atopic than unselected schoolchildren. Atopy was significantly more frequent and the onset of coeliac disease later for B8/DR3 ${ }^{-}$patients than $\mathrm{B} 8 / \mathrm{DR}^{+}$patients. There was no obvious relation between DR7 and atopy. It is concluded that atopy predisposes to coeliac disease partly independently of the HLA-DR3 associated disease susceptibility gene(s), and that different mechanisms may operate in the pathogenesis in coeliac disease patients with and without atopy.

Adult patients with coeliac disease have been reported to suffer from an increased frequency of atopic disorders. ' It has been suggested that the cause lies in the immunodeficiency of coeliac disease patients and the consequent decreased mucosal protection against allergens. In a recent study atopic history was observed significantly more often in families of children with coeliac disease than among controls. $^{2}$

Coeliac disease is associated with the HLA antigens $\mathrm{B} 8,{ }^{3} \mathrm{D} / \mathrm{DR} 3{ }^{4}$ and $\mathrm{D} / \mathrm{DR} 7^{56}$ in all Caucasian populations studied. Association with HLA-B8 and DR3 has been previously reported for Finnish children with coeliac disease.

As only little information on atopy in paediatric coeliac disease patients has been available, we undertook a study of the relation between atopy and HLA antigens in children with coeliac disease.

\section{Methods}

PATIENTS

Forty-two coeliac disease patients of 4 years of age or more regularly attending the gastroenterological outpatient clinic of Helsinki University Children's Hospital and consecutively seen between 1 September and 30 November 1980 were asked to

Address for correspondence: Dr Matti Verkasalo. Children's Hospital. University of Helsinki. Stenbäck Street 11. SF-(0)290) Helsinki 29. Finland.

Received for publication 14 June 1982 participate in an atopy evaluation, with their parents' consent. The median age of the patients was 13 years; there were 28 girls with a median age of 13 years, and 14 boys with a median age of 14 years. The diagnosis of coeliac disease was based on repeated proximal jejunal biopsies in 32 patients and on single intestinal biopsy with typical histological lesion and clinical improvement in 10 patients whose disease was late in onset: the median age of diagnosis of coeliac disease in these 10 patients was 10.85 years.

The reference material for the atopy evaluation was provided by recent studies of allergy in unselected schoolchildren from southeastern Finland. ${ }^{89}$ The control material for HLA antigen studies consisted of the Finnish Red Cross Blood Transfusion Service habitual series of 900 healthy blood donors for HLA-A, B, and C loci. The results of the HLA-DR antigen analysis were compared with those of a series of 88 unrelated Finnish subjects, most of them healthy volunteers typed for the 8th International Histocompatibility Workshop, and the remainder previously healthy cadaver kidney donors.

The atopic histories of the patients and their families were recorded on a detailed questionnaire identical to that used by Haahtela et al. ${ }^{89}$ In clinical examination special emphasis was placed on the manifestations of atopy and the exclusion of possible coexisting dermatitis herpetiformis. 
After informed consent, blood was drawn for determination of total serum $\operatorname{IgE}$ and specific $\operatorname{IgE}^{10}$ against timothy grass pollen, cat dander, egg, cow's milk, and wheat flour, as well as for HLA antigen identification. As part of the routine patient evaluation, serum $\operatorname{IgA}$ and precipitating antibodies against cow's milk and gluten ${ }^{11}$ were studied. Each patient also had a series of skin prick tests performed by a nurse specialised in paediatric allergy. Standardised extracts ${ }^{12}$ of the following allergens were used: birch, timothy grass, orchard grass, mugwort, house dust mite, and danders of dog, cat, and horse. Additional skin prick tests were performed with conventional extracts of house dust, egg, fish, pea, nut, cow's milk, and wheat flour. Any additional prick test considered clinically necessary was performed but excluded from the results of this study.

Children were considered atopic if they had asthma (a history of episodic bronchial wheezing and expiratory difficulty without respiratory infection), allergic rhinoconjunctivitis (episodic swelling of the eyes and watery discharge from the nose associated with proven or strongly suspected allergen), atopic dermatitis (pruritic dermatitis often associated with dry skin and white dermographism), urticaria in response to a known allergen, or gastrointestinal allergy (vomiting and/or diarrhoea after ingestion of a dietary allergen, proven by elimination and challenge tests.

HLA typing was performed on peripheral blood lymphocytes using a modified microlymphocytotoxicity test ${ }^{13}$ for $\mathrm{A}, \mathrm{B}$, and $\mathrm{C}$ locus antigens, and a modified two-colour fluorescence test ${ }^{14}$ for DR locus antigen determination.

In statistical analysis of the results, Student's $t$ test, $\chi^{2}$, or Fisher's exact test was used, as applicable.

\section{Results}

The results of the study of HLA antigens are presented in Table 1 together with the corresponding control figures. HLA-DR antigens could be identified satisfactorily in 41 patients, and displayed the expected HLA associations.

Atopic disorders in coeliac disease patients are described in Tables 2 and 3. Patients with coeliac disease were observed to be more atopic than the controls. Atopic dermatitis, gastrointestinal allergy and possibly also asthma were more frequent in coeliac disease patients than in unselected schoolchildren. Of identifiable allergens, pollens and foods are responsible for the observed excess of atopies in coeliac disease patients.

The correlation between history of atopy and prick or radioallergosorbent (RAST) tests was best in pollen sensitivity: of nine coeliac disease patients reporting hay fever all had positive skin prick and RAST specific IgE against pollens. An additional five asymptomatic patients had positive prick tests and three of these also had RAST specific IgE against pollens. With food allergies the correlation between history and testing was less clear: 11 patients reported sensitivities to various foods, six of them had positive prick tests and five of these had RAST specific IgE against at least one dietary allergen. Of patients not reporting food sensitivities 10 showed positive skin prick tests and eight RAST specific IgE against dietary allergens. Prick tests against animal danders and house dust were in each case positive in 16 patients; only one patient had reported symptoms on animal contact.

In the five cases where RAST specific IgE against wheat flour was detected the duration of gluten free diet had been relatively short: a mean of 3.0 years compared with a mean of 9.1 years in the atopic coeliac disease patients in whom wheat-RAST was negative.

Precipitating antibodies to gluten excluded positive RAST test against wheat flour in all cases. Serum $\operatorname{IgA}$ and $\operatorname{IgE}$ did not show any correlation: serum IgA less than -2 SD below the mean for age did not coincide with raised serum $\operatorname{IgE}$, which was observed in nine patients.

Table 3 also shows the correlation between the HLA antigen and atopy evaluation. Several atopic features were significantly more often seen in coeliac

Table 1 HLA antigens in childhood coeliac disease

\begin{tabular}{|c|c|c|c|c|c|c|c|}
\hline \multirow[b]{2}{*}{ Antigen } & \multicolumn{2}{|c|}{ Coeliac disease patients } & \multicolumn{2}{|l|}{ Controls } & \multirow[b]{2}{*}{$R R$} & \multirow[b]{2}{*}{$\chi^{2}$} & \multirow[b]{2}{*}{$p$} \\
\hline & $n$ & $\%$ & $n$ & $\%$ & & & \\
\hline B8 & $28 / 42$ & $66 \cdot 7$ & $180 / 90()$ & $2(1 \cdot()$ & $8 \cdot()$ & 5()$\cdot 7921$ & $<() \cdot()() 1$ \\
\hline DR3 & $35 / 41$ & $85 \cdot 4$ & $21 / 88$ & 23.9 & $18 \cdot 6$ & $+3 \cdot 0652$ & $<(0 \cdot()(0) 1$ \\
\hline DR7 & $27 / 41$ & $65 \cdot 9$ & $10 / 88$ & $11 \cdot 4$ & $15 \cdot(1)$ & $4(1) .5976$ & $<() \cdot(0) 1$ \\
\hline
\end{tabular}

$\mathrm{RR}=$ relative risk . 


\begin{tabular}{|c|c|c|c|c|c|}
\hline & Asthma & Hay fever & $\begin{array}{l}\text { Atopic } \\
\text { dermatitis }\end{array}$ & $\begin{array}{l}\text { Gastro- } \\
\text { intestinal } \\
\text { atopy }\end{array}$ & $\begin{array}{l}\text { Any } \\
\text { symptoms }\end{array}$ \\
\hline 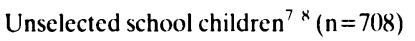 & $30(4 \cdot 2 \%)$ & $173(24 \%)$ & $195(28 \%)^{*}$ & - & $292(41 \%)$ \\
\hline Coeliac disease patients $(n=42)$ & $3(7 \cdot 1 \%)$ & $9(21 \%)$ & $19(45 \%)^{*}$ & $2(5 \%)$ & $24(57 \%)$ \\
\hline Of these HLA B8+ & $1 / 3$ & $5 / 9$ & $9 / 19$ & $1 / 2$ & \\
\hline HLA-DR3+ & $3 / 3$ & $4 / 9 \div$ & $16 / 19$ & $1 / 2$ & \\
\hline HLA-DR7+ & $2 / 3$ & $8 / 9$ & $11 / 19$ & $2 / 2$ & \\
\hline
\end{tabular}

${ }^{*}$ Difference between these figures is significant $(p<0 \cdot(05)$.

+ This figure differs significantly from that for all coeliac disease patients $(p<0 \cdot(05)$.

disease patients negative for HLA-B8 or DR3 than in those carrying the mentioned antigens. The diagnosis of coeliac disease was reached latest in DR $3^{-}$patients. Interestingly enough, there was no obvious correlation between DR7 antigen possession and atopy in coeliac disease patients: if anything. $\mathrm{DR} 7^{+}$patients reported hay fever and had positive wheat-RAST more often than the rest of the study group.

In addition to HLA-DR3, also the length of breast feeding influenced the age of onset of coeliac disease: the median duration of nursing in the patients with coeliac disease diagnosed before their first birthday was 30 days as compared with 60) days in those with later onset of the disease. Subgroups with and without HLA-B8. DR3, or DR7 did not differ from each other with regard to the length of breast feeding. The age at the introduction of cereals into the infant's diet did not affect the age of onset of coeliac disease.

\section{Discussion}

The results of a study on atopy in paediatric coeliac disease patients are presented. Coeliac disease patients were observed to have atopy more often than unselected school children. Especially atopic dermatitis was observed with increased frequency in coeliac disease patients. This may indicate an overall vulnerability of the skin in patients with coeliac disease, another manifestation of which would be the cutaneous lesion observed in dermatitis herpetiformis.

The possibility that atopic eczema was misdiagnosed for dermatitis herpetiformis as the cause of pruritus is remote in this study: most of our patients were young when gluten-free diet was instituted, and this would prevent dermatitis herpetiformis from becoming manifest.

The penetration of dietary antigens is increased in untreated coeliac disease, as indicated by the increased frequency of precipitating antibodies to cow's milk and egg white proteins. ${ }^{15}$ It may be speculated that, in patients prone to atopy, this mucosal permeability may lead to production of reaginic antibodies to food allergens and thus to increased frequency of gastrointestinal hypersensitivity. This in turn may cause increase in the frequency of eczema because of food allergy. On the other hand, patients with eczema and food allergy have been reported to have increased intestinal permeability. ${ }^{16}$ Whether this could be the only factor predisposing atopics to coeliac disease remains a question to be answered.

The HLA antigen study revealed the expected associations in the whole study group. When the group is divided into subgroups according to HLA antigen status, interesting differences emerge: children with the 'classical' HLA antigens associated with coeliac disease, B8, and DR3 exhibit early onset of the disease and a similar frequency of atopic disorders to the control chil ${ }^{\text {s. }} \mathrm{n}$; those who lack HLA-B8 or DR3 have later onseı of coeliac disease and are clearly more often atopic. We conclude that atopy predisposes to coeliac disease partly independently of the HLA-DR3 associated disease susceptibility gene or genes. A similar phenomenon of autoimmune predisposition partly independent of the HLA system has been observed in myasthenia gravis. ${ }^{17}$ It is interesting to note that there is little or no relation between HLA-DR7 and atopy in coeliac disease patients. This may be taken to indicate that the mechanisms by which DR3 and DR7 render their carriers vulnerable to coeliac disease are separate and different.

Patients who had reaginic antibodies to wheat flour did not have precipitating antibodies to gluten at the same time, even though they had the shortest period of gluten elimination. A possible explanation for this is that reaginic response to gluten constitutes a subgroup of gluten sensitivity in coeliac disease. different from that in the majority of patients where other immune mechanisms operate. ${ }^{\text {s }}$ All patients with positive wheat-RAST had HLA-DR7. while 


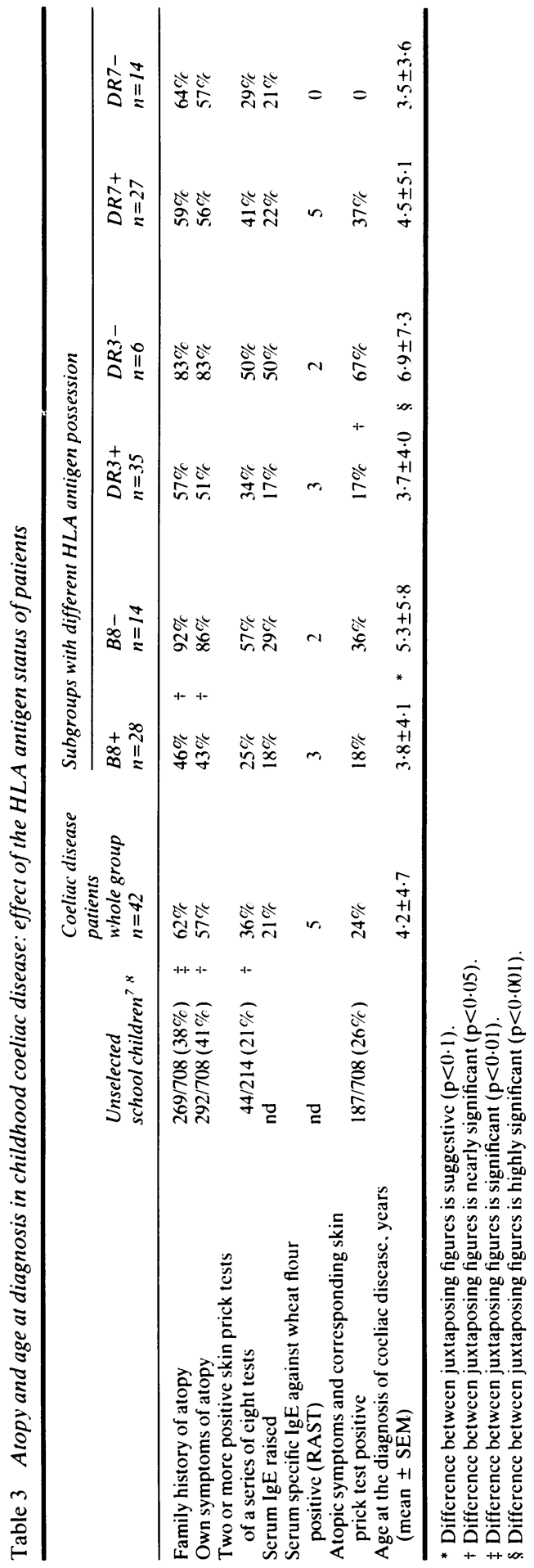


only about half of them had B8 or DR3.

In a previous report on the subject, ${ }^{1}$ atopy was suggested to be a consequence of immunodeficiency in coeliac disease. Were this the case, one would expect to find no difference between HLA antigen distribution in coeliac disease patients with and without atopy, as association between HLA and atopy has been observed to be weak and partly with HLA-B8 and DW3 antigens also associated with coeliac disease. ${ }^{19}$ Our results, however, support the view that the excess of atopy in coeliac disease patients is mostly because of the increased susceptibility of atopics to develop coeliac disease.

This study has been supported by grants from the Foundation for Paediatric Research and the Foundation for Nutrition Research. The excellent technical assistance of Mrs Pirjo Vartiainen and Mrs Toive Taulamo is gratefully acknowledged.

\section{References}

1 Hodgson HJF. Davies RJ. Gent AE. Hodson ME. Atopic disorders and adult coeliac disease. Lancet 1976: 1: 115-7.

2 Rossipal E. On the association of coeliac disease with allergic disorders. A study of family histories of 110 families with one or two children with coeliac disease. In: McConnell RB. ed. The genetics of coeliac disease. Lancaster: MTP Press. 1981: 85-92.

3 Stokes PL. Asquith P. Holmes GKT. Mackintosh P. Cooke WT. Histocompatibility antigens associated with adult coeliac disease. Lancet 1972: 2: 162-4.

4 Keunig JJ. Peña AS, van Leeuwen A. van Hoof JP. van Rood JJ. HLA-DRW3 association with coeliac disease. Lancet 1976: 1: 506-11.

5 Albert E. Harms K. Bertele R et al. B-cell alloantigens in coeliac disease. In: McNicholl B, McCarthy CF. Fottrell PF, eds. Perspectives in coeliac disease. Lancaster: MTP Press. 1977: 123-9.
6 DeMarchi M, Borelli I. Olivetti E et al. Two HLA-D and DR alleles are associated with coeliac disease. Tissue Antigens 1979; 14: 309-16.

7 Koivisto VA. Kuitunen P. Tiilikainen A. Äkerblom HK. HLA antigens in patients with juvenile diabetes mellitus. coeliac disease and both of these diseases. Diabete Metab 1977: 3: 49-53.

8 Haahtela TMK. The prevalence of allergic conditions and immediate skin test reactions among Finnish adolescents. Clin Allergy 1979; 9: 53-60).

9 Haahtela T. Heiskala M. Suoniemi I. Allergic disorders and immediate skin test reactivity in Finnish adolescents. Allergy 1980): 35: 433-41.

10 Pharmacia Fine Chemicals, PRIST and RAST, Uppsala, Sweden.

11 Crowle AJ. A simplified micro double diffusion agar precipitin technique. J Lab Clin Med 1958: 52: 784-7.

12 Aas K. Backman A. Belin L. Wecke B. Standardization of allergen extracts with appropriate methods. The combined use of skin prick testing and radioallergosorbent tests. Allergy 1978; 33: 130-7.

13 Turunen $O$. Lundqvist $C$. Julin $M$. Holmlund $G$, Tiilikainen A. de la Chapelle A. Stimulatory and cytotoxic activity on human adult and fetal lymphocytes by heterologous antihuman fetal lymphocyte sera. Transplantation 1979: 27: 304-8.

14 van Rood JJ, van Leeuwen A. Ploem JS. Simultaneous detection of two cell populations by two-colour fluorescence and application to the recognition of B-cell determinants. Nature 1976; 262: 795-7.

15 Grüttner R. Stern M. Coeliakie - Klinik und Pathogenese. Mschr Kinderheilk 1980; 128: 109-17.

16 Jackson PG. Lessof MH. Baker RWR. Ferrett J. MacDonald DM. Intestinal permeability in patients with eczema and food allergy. Lancet 1981; 1: 1285-6.

17 Pirskanen R. Genetic associations between myasthenia gravis and the HL-A system. J Neurol Neurosurg Psychiatr 1976: 39: 23-33.

18 Strober W. An immunologic 11 theory of glutensensitive enteropathy. In: McNicholl B. McCarthy CF. Fottrell PF, eds. Perspectives in coeliac disease. Lancaster: MTP Press. 1977: 169-81.

19 Marsh DG. HLA and allergy. In: Steffen C. Ludwig H. eds. Clinical immunology and allergology. Amsterdam: Elsevier/North Holland Biomedical Press. 1981: 15766. 